Figure. Observed proportions of patients with change from baseline in $\mathrm{mTSS}>\mathrm{SDC}$ at week 52 based on baseline haemoglobin levels. ADA, adalimumab; BARI, baricitinib; $\mathrm{CFB}$, change from baseline; $\mathrm{Hb}$, haemoglobin; IR, inadequate response; mTSS, modified total Sharp score; MTX, methotrexate; PBO, placebo; SDC, smallest detectable change.

Figure A. RA-BEGIN (no/minimal previous MTX; $\mathrm{N}=545$ )

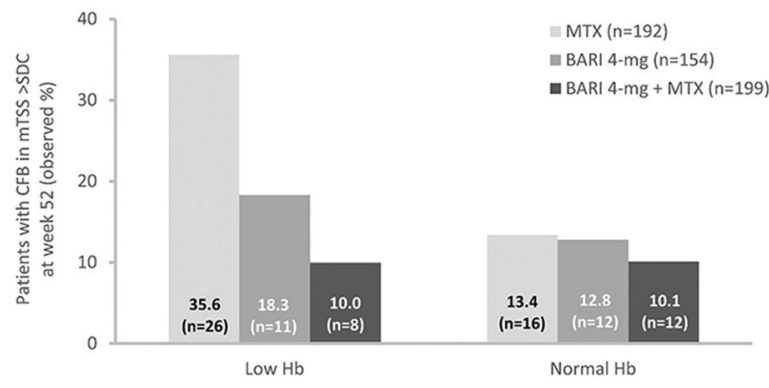

Figure B. RA-BEAM (MTX IR, on background MTX; $N=1235$ )

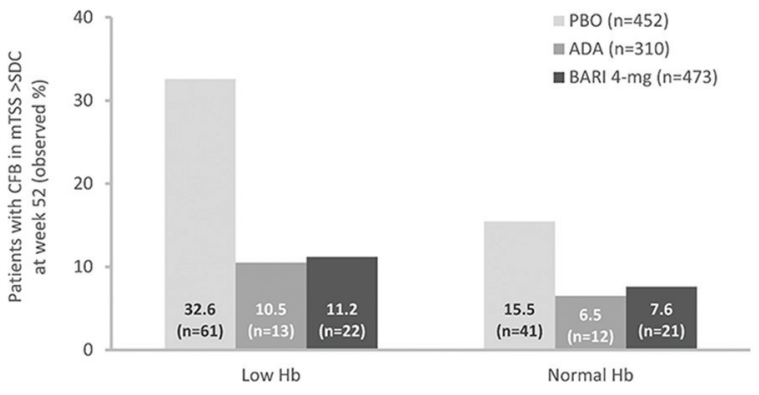

Disclosure of Interests: Burkhard Moeller Consultant for: Swissmedic Human Medicines Expert Committee Member (regulatory agency), Patrick Durez Speakers bureau: Bristol-Myers Squibb, Eli Lilly, Sanofi, Celltrion, Axel Finckh Grant/research support from: Bristol-Myers Squibb, Pfizer Inc, Consultant for: AbbVie, A2Bio, Bristol-Myers Squibb, MSD, Roche, Pfizer Inc, and UCB, Pedro López-Romero Shareholder of: Eli Lilly and Company, Employee of: Eli Lilly and Company, Clementine Perrier Shareholder of: Eli Lilly and Company, Employee of: Eli Lilly and Company, Francesco de Leonardis Shareholder of: Eli Lilly and Company, Employee of: Eli Lilly and Company, Inmaculada De La Torre Shareholder of: Eli Lilly and Company, Employee of: Eli Lilly and Company, Peter C. Taylor Grant/research support from: Celgene, Galapagos, Eli Lilly, UCB, Consultant for: AbbVie, Galapagos, Gilead, Eli Lilly, Pfizer Inc

DOI: 10.1136/annrheumdis-2019-eular.976

\section{SAT0103 LONGITUDINAL PRE-DISEASE TO DISEASE SERUM SAMPLES IDENTIFY BIOMARKERS THAT ARE UPREGULATED PRIOR TO THE DIAGNOSIS OF RHEUMATOID ARTHRITIS}

Sunil Nagpal ${ }^{1}$, Matthew J. Loza ${ }^{1}$, Suzanne Cole ${ }^{1}$, Brittney Scott ${ }^{1}$, Renee Laird ${ }^{2}$, Frederic Baribaud ${ }^{1}$, lan Anderson ${ }^{1}$, Navin Rao ${ }^{1}$, Mark Riddle ${ }^{3}$, Chad Porter ${ }^{2}$. ${ }^{1}$ Janssen Research and Development, Immunology Therapeutic Area, Spring House, United States of America; ${ }^{2}$ Navy Medical Research Center, Enteric Diseases Department, Silver Springs, United States of America; ${ }^{3}$ Uniformed Services University, Preventive Medicine and Biostatistics, Bathesda, United States of America

Background: Rheumatoid Arthritis (RA) patients have autoantibodies reactive against several citrullinated peptides that develop 10-15 years before the clinical onset of disease. However, there is a more limited understanding of serological biomarkers of disease progression, specifically those that are upregulated in patients 6-18 months before the clinical diagnosis of RA.

Objectives: Identification of biomarkers that could classify patients 6-18 months before the clinical diagnosis of RA.

Methods: We identified 500 subjects with RA, 500 with Reactive Arthritis (ReA) (based on ICD9-CM code) as well as 250 age, gender and timematched healthy control subjects from the Defense Medical Surveillance System (DMSS). For each subject, up to four serum samples were obtained from the Department of Defense (DoD) serum repository, 3 predisease diagnosis points and one immediately prior to or around disease diagnosis. A discovery subset of these serum samples was assessed for soluble PD-1 (sPD-1), as well as 497 protein analytes measured by SomaLogic SOMAscan proteomic platform.

Results: Serum levels of SPD-1 increased over time from pre-diagnosis to RA but trended to decrease over time in ReA subjects and healthy controls. A composite score of 24 SOMAscan analytes associated with recently diagnosed RA increased in serum 6-8 months before RA diagnosis and, to a lesser extent, before ReA diagnosis. IFN-inducible chemokines CXCL9 (MIG), CXCL10 (IP-10), CXCL12 (I-TAC), and CXCL13 (BLC) increased over time preceding RA but not ReA diagnosis. Acute phase proteins (CRP, SAA, haptoglobin) and MMP-3 increased before diagnosis in serum samples from both RA and ReA patients. These protein analytes represent potential new biomarkers of early RA.

Conclusion: Samples from the US DoD serum repository have identified novel biomarkers (SPD-1 and IFN-inducible chemokines) of early RA that are elevated within 8 months of disease diagnosis. These protein analytes may afford the opportunity to develop novel biomarker(s) for diagnosis and disease progression to early RA. An understanding of the role of these proteins could provide increased insight into RA pathogenesis prior to disease diagnosis.

Disclosure of Interests: Sunil Nagpal Shareholder of: Johnson \& Johnson, Employee of: Janssen Research \& Development, LLC, Matthew J Loza Shareholder of: Johnson \& Johnson, Employee of: Janssen Research \& Development, LLC, Suzanne Cole Shareholder of: Johnson \& Johnson, Employee of: Janssen Research \& Development, LLC, Brittney Scott Shareholder of: Johnson \& Johnson, Employee of: Janssen Research \& Development, LLC, Renee Laird: None declared, Frederic Baribaud Shareholder of: Johnson \& Johnson, Employee of: Janssen Research \& Development, LLC, Ian Anderson Shareholder of: Johnson \& Johnson, Employee of: Janssen Research \& Development, LLC, Navin Rao Shareholder of: Johnson \& Johnson, Employee of: Janssen Research \& Development, LLC, Mark Riddle: None declared, Chad Porter: None declared DOI: 10.1136/annrheumdis-2019-eular.3837

\section{SAT0104 INITIAL EVIDENCE FOR THE NEED OF A DUAL TREAT- TO-TARGET STRATEGY IN PATIENTS WITH RHEUMATOID ARTHRITIS}

Claudia Oppenauer ${ }^{1}$, Martina Durechova ${ }^{2}$, Michael Zauner $^{2}$, Martin Posch $^{3}$, Susanne Urach ${ }^{3}$, Klaus Machold ${ }^{2}$, Daniel Aletaha ${ }^{2}$, Ricardo Ferreira ${ }^{4}$,

Tanja Stamm'. ${ }^{1}$ Medical University of Vienna, Section for Outcomes Research, Vienna, Austria; ${ }^{2}$ Medical University of Vienna, Department of Medicine III, Division of Rheumatology, Vienna, Austria; ${ }^{3}$ Medical University of Vienna, Section for Medical Statistics, Vienna, Austria; ${ }^{4}$ Centro Hospitalar e Universitário de Coimbra, Coimbra, Portugal

Background: The treat-to-target (T2T) strategy has been established as a key concept in the management of patients with rheumatoid arthritis (RA) aiming to achieve remission or at least low disease activity [1]. However it might be more important for patients to set individual treatment goals which are related to their specific life context. For this reason, Ferreira at al [2] recently proposed a dual T2T strategy including both biological remission and individual patient reported symptom remission. It is currently unclear how achieving biological remission and individual patient treatment goals overlap and whether patients who reach the T2T target also reach their individual treatment goals

Objectives: To explore if achieving T2T biological remission and individual patient treatment goals overlap in RA patients with initially low, moderate, or high disease activity (LDA, MDA, HDA).

Methods: We recruited a consecutive convenience sample of patients with RA diagnosed according to ACR/EULAR criteria and with LDA, MDA, or HDA into this observational longitudinal study. Disease activity was measured with the Clinical Disease Activity Index (CDAI) and the individual patient goals were assessed with the Goal Attainment Scale (GAS) at baseline and after three to five months. The number and proportion of patients who reach the T2T target, but not their individual goals and vice versa were calculated.

Results: We enrolled 162 patients in the study (131 [80.9\%] women, median age 59.0, IQR= 49-71). 101 patients $(62 \%)$ had a follow up visit with no missing data after three months. Of these, $48(47.6 \%)$ patients had LDA, $43(42.6 \%)$ had MDA, and $10(9.9 \%)$ had HDA at baseline. 62 patients $(61.4 \%)$ reached remission $(14.7 \%)$ or stayed in LDA (46.1\%), and 66 patients $(65.3 \%)$ achieved their individual goal(s) (Table 1). $18(17.8 \%)$ patients did not achieve their individual treatment goals, even if T2T was successful and $22(21.8 \%)$ patients achieved their individual goals despite not reaching remission or LDA

Conclusion: Our results indicate that most patients achieving T2T attain their individual treatment goals but a respectable part of T2T outcomes 
had to be supplemented by the individual patient reported treatment goals.

\section{REFERENCES}

[1] Smolen JS, Landewe R, Bijlsma J, et al. EULAR recommendations for the management of rheumatoid arthritis with synthetic and biological diseasemodifying antirheumatic drugs: 2016 update. Ann Rheum Dis 2017; 76(6): 960-977.

[2] Ferreira RJO, Ndosi M, de Wit M, et al. Dual target strategy: a proposal to mitigate the risk of overtreatment and enhance patient satisfaction in rheumatoid arthritis. Ann Rheum Dis 2018; [Epub ahead of print 22 Aug 2018].

Table 1. Comparison of achieved T2T and individual patient goals

\begin{tabular}{lcccc}
\hline \multicolumn{5}{c}{ T2T achieved, $\mathrm{n}(\%)$} \\
\hline Patient goal(s) achieved, $\mathrm{n}$ & Yes & Yes & No & Overall \\
$\begin{array}{l}\text { (\%) } \\
\text { Overall }\end{array}$ & No & $(43.6)$ & 22 & $66(65.3)$ \\
& & 18 & $(21.8)$ & \\
& & $(17.8)$ & $(16.8)$ & $35(34.7)$ \\
& 62 & 39 & 101 \\
& & $(61.4)$ & $(38.6)$ & $(100.0)$ \\
\hline
\end{tabular}

Acknowledgement: We want to thank all patients who participated in this study. Further thanks to the students Marie Louise Brand, Saskia Langthaller, Hanna Mües and Jim Schmeckenbecher for assisting in patient recruitment.

Disclosure of Interests: Claudia Oppenauer: None declared, Martina Durechova: None declared, Michael Zauner: None declared, Martin Posch: None declared, Susanne Urach: None declared, Klaus Machold Grant/ research support from: Abbvie, Daniel Aletaha Grant/research support from: AbbVie, Bristol-Myers Squibb, and MSD, Consultant for: AbbVie, Bristol-Myers Squibb, Eli Lilly, Janssen, Medac, Merck, MSD, Pfizer Inc, Roche, and UCB, Speakers bureau: AbbVie, Bristol-Myers Squibb, Eli Lilly, Janssen, Medac, Merck, MSD, Pfizer Inc, Roche, and UCB, Ricardo Ferreira: None declared, Tanja Stamm Grant/research support from: TS has received grant support from AbbVie., Paid instructor for: TS has received speaker fees from AbbVie, Janssen, MSD, Novartis, and Roche. DOI: 10.1136/annrheumdis-2019-eular.3282

\section{SAT0105 HAND DISABILITY IN RHEUMATOID ARTHRITIS: AN ENGINEERED GLOVE FOR THE COMPUTERISED QUANTIFICATION OF THE DAMAGE}

Massimo Patanè $^{1}$, Luca Carmisciano ${ }^{2}$, Emanuele Gotelli ${ }^{1}$, Veronica Tomatis ${ }^{1}$, Federica Goegan ${ }^{1}$, Elisa Alessandri ${ }^{1}$, Massimo Ghio ${ }^{1}$, Alessio Signori ${ }^{2}$, Maurizio Cutolo ${ }^{1}{ }^{1}$ Research Laboratory and Academic Division of Clinical Rheumatology, Department of Internal Medicine, IRCCS Polyclinic Hospital San Martino, University of Genoa, Genoa, Italy, ${ }^{2}$ Biostatistics Unit, Department of Health Sciences, University of Genoa, Genoa, Italy

Background: Tenderness, swelling and loss of motility of the joints are the main determinants of the disability function (DF) of Rheumatoid Arthritis (RA) patients (RApts) ${ }^{1}$. The evaluation of DF is performed by Patient Reported Outcomes (PROs), like Health Assessment Questionnaire $(H A Q)^{2}$. The lack of objective evaluation of DF is one of the most important "unmet needs" in RA. The Hand Test System (HTS, ETT) is an engineered glove, nowadays applied for neuroscience studies to evaluate hands motility with interesting perspectives of use in other clinical research fields ${ }^{3-4}$.

Objectives: To quantify the DF of RApts by the analysis of speed and right execution of fingers opposition movement in both hands, evaluated by HTS. To verify the correspondence with the HAQ.

Methods: In this pilot study 14 consecutives RApts (3 males, 11 females, age $61 \pm 11,5$ years, mean duration of disease 11,21 $\pm 5,07$ years), classified according to 2010 ACR/EULAR criteria ${ }^{5}$, and 13 healthy controls ( $\mathrm{HC}-7$ males, 6 females, age $50 \pm 15$ years) were enrolled from the RA clinic. After consent, all participants undergone HTS test that recognizes the touches between the finger tips during the opposition movements of the hands in standard sequences of movements, after dressed the glove. A multiple finger evaluation (MFE) and a single finger evaluation (SFE) were performed using a dedicated software that provided the physician the following quantitative parameters: Touch Duration (TD), Inter Tapping Interval (ITI) and Movement Rate (MR). Average time for hand 2 minutes. RApts compiled the $\mathrm{HAQ}$ and a tender and swollen joint count of the hands was performed. Continue variables were summarized as mean and standard deviation (SD) or median and interquartile range
(IQR), discrete variables were summarized with count and percentage. Variables with skewed distribution was converted to natural logarithm. Ttest was used to compare log glove parameters between groups. Pearson's $r$ and $p$ value were used to report the correlation between log-converted glove parameters and $\mathrm{HAQ}$ score.

Results: In MFE, glove parameters TD and ITI were significantly higher in RApts (TD $257.34 \pm 123.93 \mathrm{~ms}$, ITI $377.8 \pm 211.35 \mathrm{~ms}$ ) than HC (TD $172.25 \pm 59.36 \mathrm{~ms}$, ITI $177.98 \pm 78.53 \mathrm{~ms})(p=0.004$ and $\mathrm{p}<$ $0.001)$ and MR was significantly lower in RApts $(1.51 \pm 0.47 \mathrm{~Hz})$ compared to $\mathrm{HC}(2.87 \pm 0.9 \mathrm{~Hz}) \quad(p<0.001)$. TD of RApts had a significant correlation with the total score of the $\mathrm{HAQ}$ (Pearson $r=0.79, p=$ 0.001). In SFE non-active fingers (NAF, not swollen and not tender) of RApts seemed to perform slightly better than a clinically active finger (AF) but significantly worse than average HC finger (ANOVA, $\mathrm{p}<0.001$ ). Conclusion: HTS is a new easy and totally safe tool that seems to quantify in an objective manner the hand DF in RApts. The significant correlation found with $\mathrm{HAQ}$ underlines the value and veracity of self assessment tools in clinical practice. Further studies are ongoing with larger number of RApts to validate its application to monitor the improvement or the worsening of RA in order to optimize pharmacological treatments. The study is now extended in other Rheumatic and Musculoskeletal Diseases.

\section{REFERENCE}

[1] Hakkinen A, et al. Ann Rheum Dis. 2005; 64:59-63. 2 Fries J, et al. Arthritis Rheum. 1980; 23:137-45. 3 Bonzano L, et al. Eur J Neurol. 2019;26 (1):162-167. 4 Signori A, et al. PLoS One. 2017 Oct 18;12(10): e0186524. 5 Aletaha D, et al. Ann Rheum Dis. 2010;69(9):1580-8.

Disclosure of Interests: None declared

DOI: 10.1136/annrheumdis-2019-eular.5777

\section{SAT0106 NOVEL SUBCLASS OF INTRAVASCULAR NON- CLASSICAL SYNOVIAL MONOCYTES ARE CRITICAL FOR RHEUMATOID ARTHRITIS}

Anna Montgomery, Deborah Winter, Harris Perlman. Northwestern University, Medicine/Rheumatology, Chicago, United States of America

Background: There are at least three populations of circulating monocytes; classical, intermediate and non-classical. We demonstrated that circulating non-classical monocytes are required for the effector phase of arthritis and spontaneous models of arthritis in mice. While the vast majority of studies on monocytes have focused those in circulation, very little is known about the monocytes in the synovium.

Objectives: The aim of this study was to examine the heterogeneity of tissue monocytes with those circulation and determine their involvement in inflammation.

Methods: Female 8-10-week-old NR4A1 $1^{-1}$, CX3CR $1^{\text {ERCre.zsGFP, and C57BI/ }}$ 6 mice were used in all studies. CX3CR $1^{\text {ERCre.zsGFP }}$ were utilized for cell tracking studies and joint shielded bone marrow chimeras via administration of tamoxifen (tam). Intravascular monocytes were identified using fluorescent anti CD45 antibody before perfusion. STIA was induced via I.V. $\mathrm{KBxN}$ sera. Monocyte populations were quantified by flow cytometry and FACS sorted for RNA-sequencing (RNA seq). Nonclassical tissue monocytes were identified $\mathrm{CD}_{4} 5^{+} \mathrm{CD} 11 \mathrm{~b}^{+}$Ly6G $\mathrm{TIM}^{-} \mathrm{CD} 64^{-} \mathrm{Ly}^{-} \mathrm{c}^{\mathrm{lo}}$ and subdivided into intravascular (CD45-labeled, $\mathrm{CD}^{+} 3^{+}$), trans-vascular (CD45-labeled $\mathrm{CD}^{\circ} 3^{-}$) and extravascular (no CD45-label). Human synovium was obtained from ultrasound guided synovial biopsies and CD45+ cells were FACSorted for single cell RNA seq.

Results: NR4A $1^{-1-}$ mice exhibit a $95 \%$ reduction in circulating Ly6c $\mathrm{c}^{\mathrm{lo}}$ monocytes but retain $L y 6 c^{10}$ cells in the joint and develop STIA. The transcriptional profiling of bulk populations of Ly $6 c^{\text {lo }}$ cells in the synovium are distinct from those circulating in the blood. We then identified three populations of $\mathrm{Ly}_{6 \mathrm{C}} \mathrm{C}^{\mathrm{lo}}$ monocytes in the joint; extra-vascular, trans-vascular cells, and intra-vascular cells using 18 color flow cytometry. Lineage tracing studies reveal that the origin of extra-vascular and trans-vascular synovial monocytes are from the embryo while the intravascular monocytes are derived post-natally. The intravascular monocytes are depleted with clodronate loaded liposomes while the extravascular and trans-vascular remain unaffected. Moreover, the intravascular monocytes rapidly expand during the first 1hour of STIA, increasing by $30 \mathrm{x}$ in population size. RA patients also display similar populations of non-classical monocytes using single cell RNA seq

Conclusion: We have identified and described three previously uncharacterized populations of non-classical monocytes cells in the joint, an intravascular adherent, a trans-vascular population and an extra-vascular 